\title{
Surgical intervention in bladder outlet obstruction due to prostatic enlargement -A prospective study
}

W. A. S. De Silva, K. M. G. N. Ranga, D. M. R. P. P. Karunaratne, K. S. C. Sirisena and D. M. A. S. Dissanayake Department of Urology, Provincial General Hospital Badulla, Badulla.

In men, obstructive lower urinary tract symptoms (LUTS) are usually due to benign prostatic hyperplasia (BPH). Carcinoma of the prostate causes obstruction when the disease is locally advanced. Failed drug therapy and complications secondary to $\mathrm{BPH}$ are the indications for surgical intervention in benign prostatic hyperplasia. Surgical procedures include bladder neck incision (BNI), transurethral resection of the prostate (TURP) and open prostatectomy. Patients with clinically malignant prostates and obstructive LUTS are subjected to transrectal biopsy of the prostate and TURP or BNI at the same sitting in our unit.

Objectives of this study were to evaluate men who underwent prostatic surgery for bladder outlet obstruction (BOO) in the Urology Unit, Provincial General Hospital (PGH) Badulla with regard to their demographic data, clinical presentation, correlation of digital rectal examination (DRE) findings with histology and various surgical interventions and their complications.

\section{Method}

It was a prospective study of 428 consecutive patients who underwent BNI, TURP or Open prostatectomy for BOO in the Urology unit PGH Badulla over a period of three years from January 2005. Data were collected in a computer database. Patients were selected for different surgical procedures on DRE findings, prostatic volume by trans-abdominal ultrasound scan (USS) of the prostate gland whenever available and cystourethroscopic findings at surgery (Table 1).

Table 1. Patient selection for surgical intervention based on DRE, USS and cystourethroscopy

\begin{tabular}{|l|l|l|l|}
\hline Intervention & DRE & $\begin{array}{l}\text { Prostatic volume by } \\
\text { Transabdominal USS }\end{array}$ & Cystourethroscopic findings \\
\hline BNI & $<20 \mathrm{~g}$ & $<20 \mathrm{ml}$ & $\begin{array}{l}\text { High bladder neck without } \\
\text { occlusive lobes }\end{array}$ \\
\hline TURP & Up to 80g & Up to 80ml & Occlusive prostatic lobes \\
\hline Open Prostatectomy & $>80 \mathrm{~g}$ & $>80 \mathrm{~g}$ & $\begin{array}{l}\text { Occlusive prostatic lobes+large } \\
\text { median lobe }\end{array}$ \\
\hline
\end{tabular}

\section{Results}

\section{Surgical Procedure (Fig. 1)}

Three hundred and twenty one patients out of 428 (75\%) underwent TURP and 104 (24.23\%) patients were subjected to BNI. Only 3 patients required open prostatectomy (Transvesical). 


\section{Surgical Procedure}

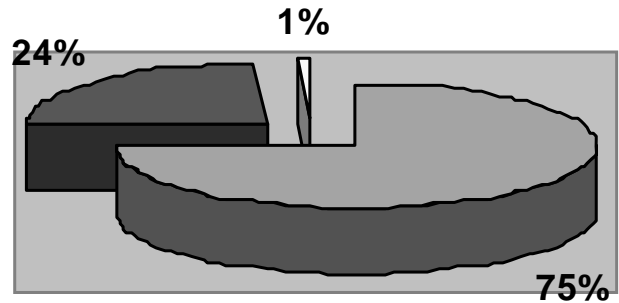

$\square$ TURP
$\square$ BNI
$\square$ OPEN

Figure 1

\section{Age Distribution (Fig. 2)}

Age ranged from 39 years to 92 years with a mean of 67 years (mean for TURP $=69.4$, for BNI $=60.4$ and for open $=75.3$ ).

\section{Age distribution}

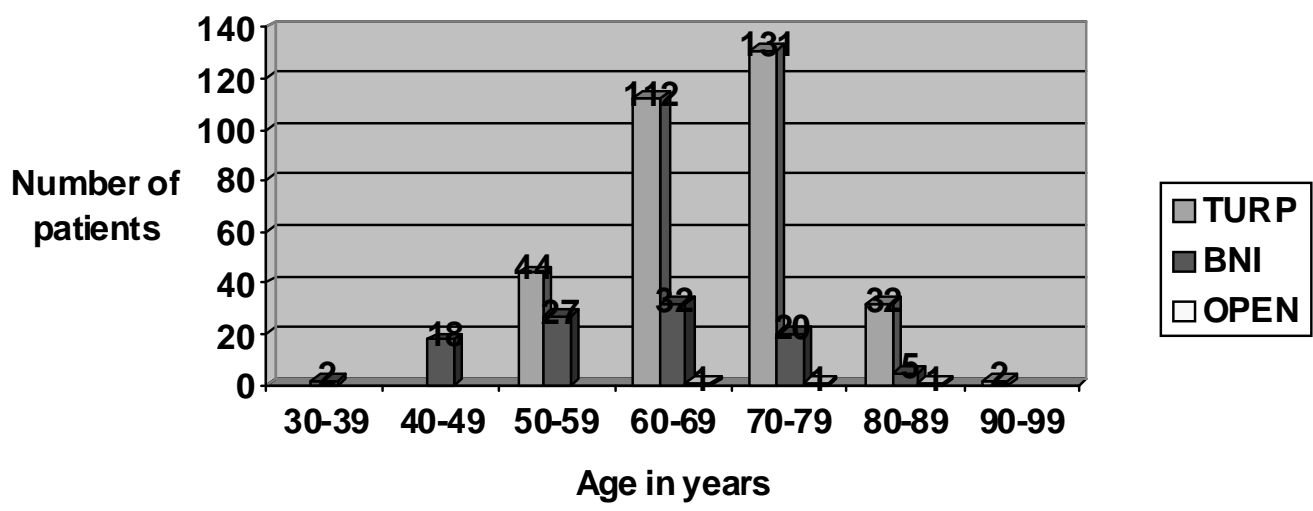

Figure 2

\section{Clinical Presentation}

All patients had obstructive LUTS. In addition to this, acute retention of urine (ARU), chronic retention of urine (CRU), vesical stones and haematuria were present in different combinations. Thirteen patients (3\%) were already diagnosed to have metastatic carcinoma of the prostate that required either BNI or TURP to relieve obstructive symptoms (channel TURPs are excluded).

\section{Duration of LUTS(428 patients)}

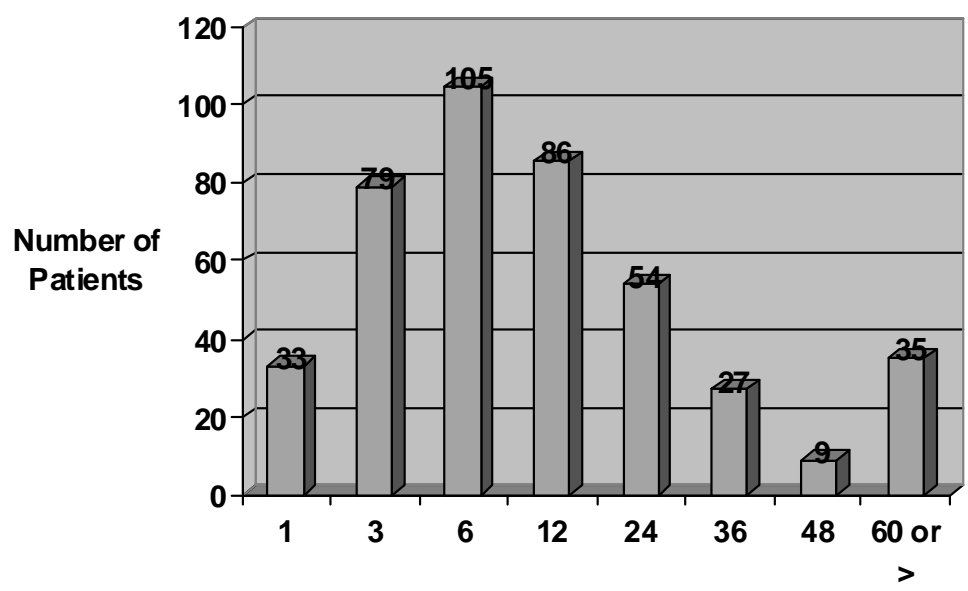

Duration in months

Figure 3 
Other symptoms in patients undergoing surgery are shown in Table 2.

Table 2. Other symptoms in men undergoing surgical intervention

\begin{tabular}{|l|c|c|c|}
\hline & TURP & BNI & OPEN \\
\hline ARU & $151(47 \%)$ & 21 & 3 \\
\hline CRU & 10 & 5 & - \\
\hline Vesical stone & 15 & - & - \\
\hline Haematuria & 23 & 7 & - \\
\hline Known prostatic cancer & 10 & 3 & 3 \\
\hline Total & 209 & 36 & \\
\hline
\end{tabular}

Among 175 patients with ARU, 131(74.86\%) were on indwelling catheters for more than one month at the time of surgery. Five patients were on suprapubic catheters.

\section{Duration of indwelling catheter}

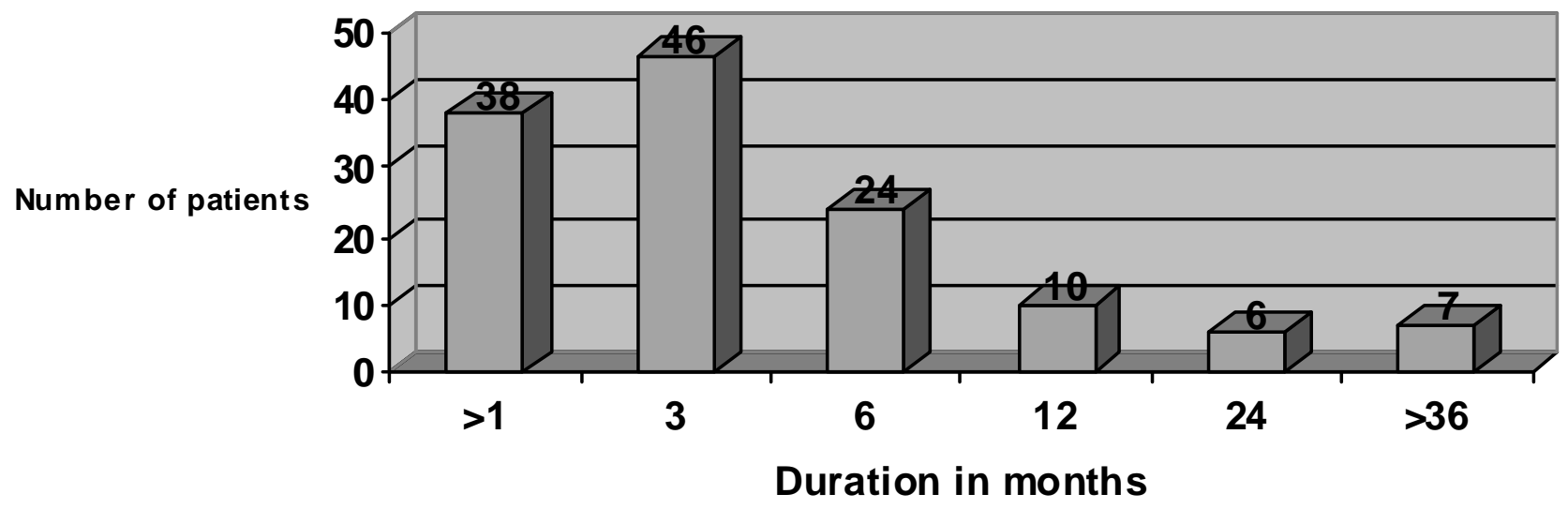

DRE

Figure 4

Correlation between DRE and histological findings is shown in Table 3.

Table 3. Correlation between DRE and histological findings

\begin{tabular}{|c|c|c|c|c|}
\hline \multirow{2}{*}{} & \multicolumn{2}{|c|}{ DRE } & \multicolumn{2}{c|}{ Histology } \\
\cline { 2 - 5 } & \multicolumn{2}{|c|}{ benign } & malignant \\
\hline \multirow{2}{*}{ TURP } & clinically benign & 233 & 224 & 62 \\
\cline { 2 - 5 } & clinically malignant & 78 & 16 & - \\
\hline \multirow{2}{*}{ BNI } & clinically benign & 96 & - & 7 \\
\cline { 2 - 5 } & clinically malignant & 8 & & 7 \\
\hline
\end{tabular}


Resection weight of prostate (321 patients) (Table 4 and Fig. 5)

Table 4

\begin{tabular}{|l|l|c|}
\hline Weight group & \multicolumn{1}{|c|}{ Description } & Total number of patients \\
\hline$<10 g$ & $n=27$ & 27 \\
\hline $10 g-20 g$ & $10 g n=71,12 g n=6,15 g n=45,16 g n=1,18 g n=8,20 g n=47$ & 63 \\
\hline $21 g-30 g$ & $22 g n=1,25 g n=34,28 g n=3,30 g n=25$ & 13 \\
\hline $31 g-40 g$ & $32 g n=1,35 g n=6,40 g n=20$ & 8 \\
\hline $41 g-50 g$ & $45 g n=5,50 g n=8$ & 4 \\
\hline $51 g-60 g$ & $55 g n=4,60 g n=4$ & 1 \\
\hline $61 g-70 g$ & $65 g n=3,70 g n=1$ & 321 \\
\hline $71 g-80 g$ & $80 g n=1$ & \\
\hline Total & & \\
\hline
\end{tabular}

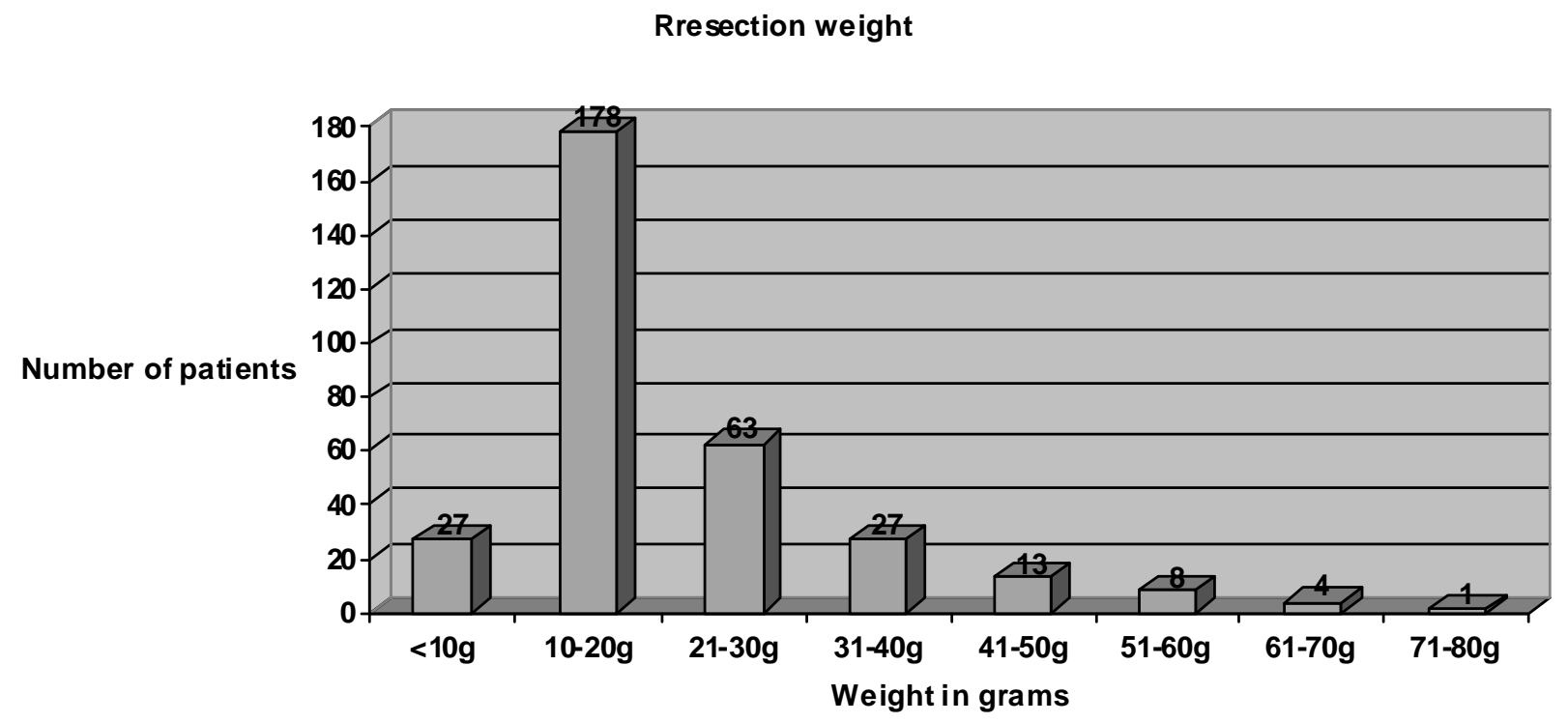

Figure 5

\section{Complications of TURP}

Significant complications related to TURP were documented in 32 patients. Thirty four complications occurred in those 32 patients. They were grouped into immediate (occurring within 24 hours), early (within 2 weeks) and late complications. 
Immediate complications
1. Intractable primary bleeding

Converted to open surgery and packing

Rediathermization before sending to ward

Postponement and re-TURP later

Blood transfusion only

2. Large capsular perforation with intractable bleeding

3. ARF necessitating haemodialysis 1

Early complications

$-$

1. Failed TWOC requiring Re-TURP

2. Transient incontinence

3. Secondary haemorrhage

1. Urethral stricture

2. Bladder neck contracture

3. Incontinence $>6$ months
10

2

2

4

2

2

1

4

2

2

2

\section{Mortality}

Only one patient out of 428 died in this series amounting to a mortality rate of 0.31 for TURP ( $n=321$ ). He had a history of IHD and died in the ICU within 24hours of TURP due to cardiogenic shock following acute myocardial infarction.

\section{Blood transfusions (Table 5)}

15 out of 321 (4.67\%) TURP patients were transfused during or immediate post TURP. Eleven patients received only one pint of blood each, three patients received 2 pints each and one patient received 6 pints.

Table 5. Resected weight, resection time and further intervention in transfused patients

\begin{tabular}{|c|c|c|c|l|}
\hline & Number of blood pints & Grams resected & Resection time & Further intervention \\
\hline 1 & 1 & 30 & 40 & Re-TURP \\
\hline 2 & 1 & 40 & 60 & Re-TURP \\
\hline 3 & 1 & 40 & 60 & Re-diathermy \\
\hline 4 & 2 & 30 & 45 & Re-TURP \\
\hline 5 & 1 & 50 & 30 & - \\
\hline 6 & 2 & 45 & 45 & Re-TURP \\
\hline 7 & 1 & 40 & 40 & - \\
\hline 8 & 2 & 45 & 35 & - \\
\hline 9 & 1 & 40 & 25 & - \\
\hline 10 & 1 & 70 & 50 & Converted to open \\
\hline 11 & 6 & 50 & 60 & Open packing \\
\hline 12 & 1 & 50 & 50 & - \\
\hline 13 & 1 & 40 & 40 & - \\
\hline 14 & 1 & 80 & 60 & - \\
\hline 15 & 1 & 65 & 45 & - \\
\hline
\end{tabular}




\section{BNI}

Bladder neck incision was carried out in 104 patients. Only one patient required TURP due to failed trial without catheter following BNI. All other patients had their indwelling catheters removed on second post operative day successfully. Some of the patients who were scheduled for BNI on DRE were subjected to TURP due to the presence of a median lobe or prominent lateral lobes though the resected volume was smaller.

\section{Open prostatectomy (Table 6)}

Only three patients in this series required open prostatectomy (0.7\%). They all underwent supra pubic transvesical prostatectomy owing to the large median lobes.

\section{Table 6.}

\begin{tabular}{|c|l|c|l|}
\hline & $\begin{array}{c}\text { Age in } \\
\text { years }\end{array}$ & $\begin{array}{c}\text { Prostate size } \\
\text { in grams }\end{array}$ & \multicolumn{1}{|c|}{ Complications } \\
\hline 1 & 76 & 210 & wound infection \\
\hline 2 & 66 & 85 & $\begin{array}{l}\text { wound infection } \\
\text { vesicocutaneous } \\
\text { fistula }\end{array}$ \\
\hline 3 & 84 & 240 & $\begin{array}{l}\text { Supra-pubic } \\
\text { wound infection }\end{array}$ \\
\hline
\end{tabular}

\section{Discussion}

Obstructive lower urinary tract symptoms in men are mainly caused by benign prostatic hyperplasia, carcinoma of the prostate and high bladder neck probably due to underlying adenoma. BPH could be managed either by medical therapy using alpha adrenergic blockers and 5-alpha reductase inhibitors or surgical intervention. Minimally invasive therapies like laser prostatectomy, transurethral needle ablation (TUNA) and transurethral electrovaporization of the prostate (TVP) are advocated for small prostates. TURP, BNI and open prostatectomy were the surgical methods available at Provincial General Hospital, Badulla.

Initial evaluation of symptomatic patients involves a detailed history and physical examination including DRE and serum prostate specific antigen (PSA) when appropriate. They are further evaluated using ultrasound scanning of the urinary tract to assess upper tracts and to record post void residual volume, and renal function tests. Nature and severity of symptoms of BOO are assessed and quantified using standard symptoms scores such as International Prostate Symptom Score (IPSS) but its applicability in our set up is questionable due to its complex nature and the level of education of the general public and hence not used routinely.

In this series patients who were diagnosed to have clinical BPH had been already treated with alpha blockers for variable periods without significant improvement and therefore underwent surgery. Patients with clinically malignant prostates and $\mathrm{BOO}$ were subjected to either BNI or TURP together with transrectal biopsy of the prostate.

$75 \%(n=321)$ of the patients in this study group underwent TURP which is the standard surgical therapy for BPH. Bladder neck incision was carried out in 104 patients as they had either small prostate on DRE with non-occlusive prostatic lobes or high bladder neck on cystoscopy. BNI is a simpler procedure acceptable for smaller prostates (1). Although open prostatectomy is very rarely practiced in the present era its value in very large prostates over 80 grams is unquestionable. Two out of 3 patients who underwent open surgery in this series had prostates of more than 200 grams in weight. According to the bar chart in Fig. 2, majority of the patients who underwent TURP $(n=243)$ and BNI $(n=52)$ belongs to the age group of 60 to 79 years. 34 patients who underwent TURP were above 80 years of age. The oldest patient in this series was 92 years and TURP was tolerated well with uneventful recovery. None of the patients below 50 years have undergone TURP and these patients had a high bladder neck with or without an underlying adenoma and responded well to BNI. All patients had obstructive LUTS and the longest duration recorded in this group was $>5$ years. Majority of the patients had symptoms for more than 6 months. ARU was a frequent association and was seen in 175 (40.88\%) patients and 131 patients had an indwelling catheter for more than one month duration prior to surgery. Surprisingly seven patients were with an indwelling catheter for more than 3 years.

Digital rectal examination is an essential part in decision making in BOO. DRE would be helpful in detecting prostatic malignancies, neurogenic causes for symptoms and the prostate size which will help to select the appropriate surgical technique although the size is not considered in deciding whether active therapy is required or not. DRE is a test that depends on the experience of the examiner and the sensitivity and specificity in detecting organ confined carcinoma of the prostate are $52 \%$ and $81 \%$ respectively (2). In this series 9 out of 233 of clinically benign prostates found to have histologically proven carcinoma of the prostate after TURP (Table 3).

Among the patients who underwent TURP patients, grams of prostatic tissue resected ranged from $<10$ to 80 
and the mean resected volume for the range of $10 \mathrm{~g}$ to 80g ( $\mathrm{n}=294)$ was 22.9g (table 4 and figure 6). Mean time for resection was 22.2 minutes.

Overall complication rate for 321 patients who underwent TURP was $9.97 \%$ (Excluding TURP syndrome and UTI), (34 complications in 32 patients). No adequate clinical and biochemical evidence were available to prove TURP syndrome and post operative UTI was not included in this study. Intractable primary bleeding was the commonest complication encountered and blood transfusion rate was $4.67 \%$ (15 patients out of 321). Table 5 describes the details pertaining to blood transfusion.

Only one patient out of 428 died in this series amounting to a mortality rate of $0.31 \%$ for TURP $(n=321)$. In a study by Mebust and co-workers on 3885 patients, immediate morbidity and mortality rates have been reported as $18 \%$ and $0.2 \%$ respectively (3).

Open prostatectomy is reserved for large prostates over 75 to 80 grams to minimize the complications from prolonged transurethral resection. Three patients who underwent open surgery in this series had more than $80 \mathrm{~g}$ prostates. This operation is ideally suited for patients with (1) a large median lobe protruding into the bladder, (2) a clinically significant bladder diverticulum, or (3) large bladder calculi (4).

\section{Conclusion}

Majority of patients who presents with $\mathrm{BOO}$ and undergo surgery are above 60 years. TURP is safe in men over 80 years. Obstructive LUTS with or without ARU is the main presentation and significant number of patients are on indwelling catheters for unacceptably long durations. This invariably affects their personal and social life and leads to catheter related problems. Although the cancer detection rate is controversial, DRE is an essential basic examination and will be of immense use in centres with substandard facilities. TURP is a safe procedure with low complication rates when done in optimized patients and significant complications could be managed effectively if close observation is maintained. BNI done in a carefully selected group of patients will have less chances of failure requiring TURP.

\section{References}

1. Edwards LE, Bucknall TE, Pittam MR, Richardson DR, Stanek J.Transurethral resection of the prostate and bladder neck incision: a review of 700 cases. British Journal of Urology 1985; 57(2): 168-71.

2. Partin AW, Yoo JK, Carter HB, et al. The use of prostate-specific antigen, clinical stage and Gleason score to predict pathological stage in men with localized prostate cancer. Journal of Urology 1993; 150: 110.

3. Mebust WK, Holtgrewe HL, Cockett ATK, Peters PC. Transurethral prostatectomy: Immediate and post operative complications. Journal of Urology 1989; 141: 243-247.

4. Han M, Alfert HJ, Partin AW. Retropubic and suprapubic open prostatectomy. In Walsh PC, Retic AB, Vaughan ED, Wein AJ (eds): Campbell's Urology, 8th ed, vol 2. Philadelphia, WB Saunders, 2002, p 1424.

\section{Authors}

W. A. Susantha de Silva, MS (Col) FRCS (Edin)

Consultant Urological Surgeon

K. M. G. N. Ranga*, MBBS

D. M. R. P. P. Karunaratne*, MBBS

K. S. C. Sirisena*, MBBS

D. M. A. S. Dissanayake*, MBBS

Senior House Officer in Urology

Department of Urology, Badulla Provincial General Hospital, Badulla, Sri Lanka. 